\title{
EL PATRIMONIO TERRITORIAL COMO ACTIVO TURÍSTICO EN LA «RAYA» DE CASTILLA Y LEÓN CON PORTUGAL ${ }^{1}$
}

\author{
Luís Alfonso Hortelano Mínguez \\ Universidad de Salamanca
}

\section{RESUMEN}

La franja fronteriza de Castilla y León con las regiones del Norte y del Centro de Portugal, en el periodo finisecular pasado, se ha posicionado como un destino emergente en el contexto de la oferta de «turismo de interior» nacional y regional. Este territorio histórico, aunque penalizado por su localización periférica y por su grado de ruralidad, ha sabido mantener y transmitir de generación en generación un rico y diverso patrimonio territorial, tanto natural como cultural. Las instituciones públicas y el sector privado, con las ayudas económicas de la política regional, de los programas de desarrollo rural y de las iniciativas de cooperación transfronteriza, han puesto en valor los recursos del medio físico, los escenarios paisajísticos y los elementos del patrimonio material e inmaterial, mediante productos enfocados al sector turístico. Sin embargo, queda aún un largo camino que recorrer con el fin de consolidar la apuesta por el turismo en la «raya» y por coser ambos lados de la frontera con proyectos comunes.

Palabras clave: Turismo; frontera; patrimonio territorial; cooperación transfronteriza; Políticas Europeas.

Recibido: 22 de julio de 2014

Devuelto para su revisión: 19 de noviembre de 2014

Aceptado: 10 de enero de 2015

Departamento de Geografía. Universidad de Salamanca. C/ Cervantes, s/n. 37002 SALAMANCA (España). E-mail: sito@usal.es

1 Este artículo recoge parte de los resultados del proyecto de investigación «Dinámica, situación actual y análisis prospectivo del iturismo de frontera? (2000-2020), como motor de desarrollo en Extremadura» (CSO201129529-C04-01), Ministerio de Ciencia e Innovación (Secretaría de Estado de Investigación. Dirección General de Investigación y Gestión del Plan Nacional de I+D+i. Subdirección General de Proyectos de Investigación). 


\title{
Territorial heritage as a touristic asset in the «Raya» of Castilla y León bordering Portugal
}

\begin{abstract}
At the end of the past century the fringe of Castilla y León bordering the Portuguese North and Centre has emerged as a destination of national and regional «inland tourism». This historical territory, though handicapped by its peripheral situation and its rural features, has preserved its rich and diverse human and natural heritage over generations. Resources consisting of physical environment, scenic landscapes and elements of the material and immaterial heritage are now touristically exploited due to public and private sector activities engaged in economic assistance through regional policies, rural and development programs and trans-border cooperation. However, there is yet a long way to go in order to consolidate the commitment to tourism in the «Raya» and to unite both sides of the border with common projects.
\end{abstract}

Keywords: Tourism; border; territorial heritage; trans-border cooperation; European Policies.

\section{LA FRANJA RAYANA DE CASTILLA Y LEÓN CON PORTUGAL: UN TERRI- TORIO PERIFÉRICO Y CONFINADO}

La franja rayana está compuesta por los términos municipales próximos a la línea de frontera, que tiene en este tramo de Castilla y León una longitud de 349 kilómetros, desde el municipio zamorano de Hermisende al norte hasta el de Navasfrías al sur de la provincia salmantina. A escala local («Unidades Administrativas Locales» UAL II), el espacio rayano castellanoleonés engloba 37 términos municipales con una extensión de 2.366,27 $\mathrm{km}^{2}$, mientras que, la superficie de las 54 freguesias de los concelhos rayanos del lado portugués asciende a $1.694,04 \mathrm{~km}^{2} \mathrm{y}$, como resultado, el «espacio transfronterizo» a esta escala abarca 91 entidades con 4.060,31 km². Sin embargo, la influencia de la frontera se extiende por las comarcas agrarias de Vitigudino y de Ciudad Rodrigo, en Salamanca, y por las de Sanabria, Aliste y Sayago, en Zamora. La superficie de las comarcas fronterizas españolas amplían el territorio de la franja fronteriza hasta los $10.203,80 \mathrm{~km}^{2}$ que, junto a los 5.697,45 km² de los concelhos portugueses de Vinhais, Bragança, Vimioso, Miranda do Douro, Mogadouro, Freixo de Espada à Cinta, Figueira de Castelo Rodrigo, Almeida y Sabugal, configuran un «área transfronteriza» de 15.901,25 km² (ver Fig. 1).

El nacimiento de este espacio fronterizo surge a raíz de la firma, el 12 de septiembre de 1297, del «Tratado de Alcañices» o «Concordia de Alcañices» ${ }^{2}$ por parte de los monarcas peninsulares en el Convento de San Francisco de esta villa zamorana. En el texto del tratado de paz se localizan y describen los hitos o mugas de los límites políticos de la frontera que

2 El tratado de la «Concordia de Alcañices» se rubricó el 12 de septiembre de 1297 por el rey de Castilla, Fernando IV «El Emplazado» (aún niño, acompañado por su madre María de Molina y su tío Enrique) y los monarcas lusos Don Dinis (el rey Labrador) y Santa Isabel (de Aragón). El reino de España y de Portugal firmarán el 29 de septiembre de 1864 el Tratado de Límites en Lisboa para el amojonamiento de la frontera que se hará efectivo en diciembre de 1906 con los trabajos topográficos para fijar con precisión las mugas o marcos que señalan la «raya». 
encuentran acomodo en los accidentes geográficos y en la red fluvial. Por estos motivos, la «raya» aúna un origen histórico con un fuerte componente geográfico que se traduce en un marcado contraste territorial donde se diferencian los tramos de «raya seca», donde persiste la continuidad espacial por sierras y por penillanuras, de los sectores de la «raya húmeda» definidos por la ruptura introducida al encajarse las corrientes fluviales en el sustrato granítico.

\section{Figura 1}

\section{FRANJA TRANSFRONTERIZA DE CASTILLA Y LEÓN CON PORTUGAL}

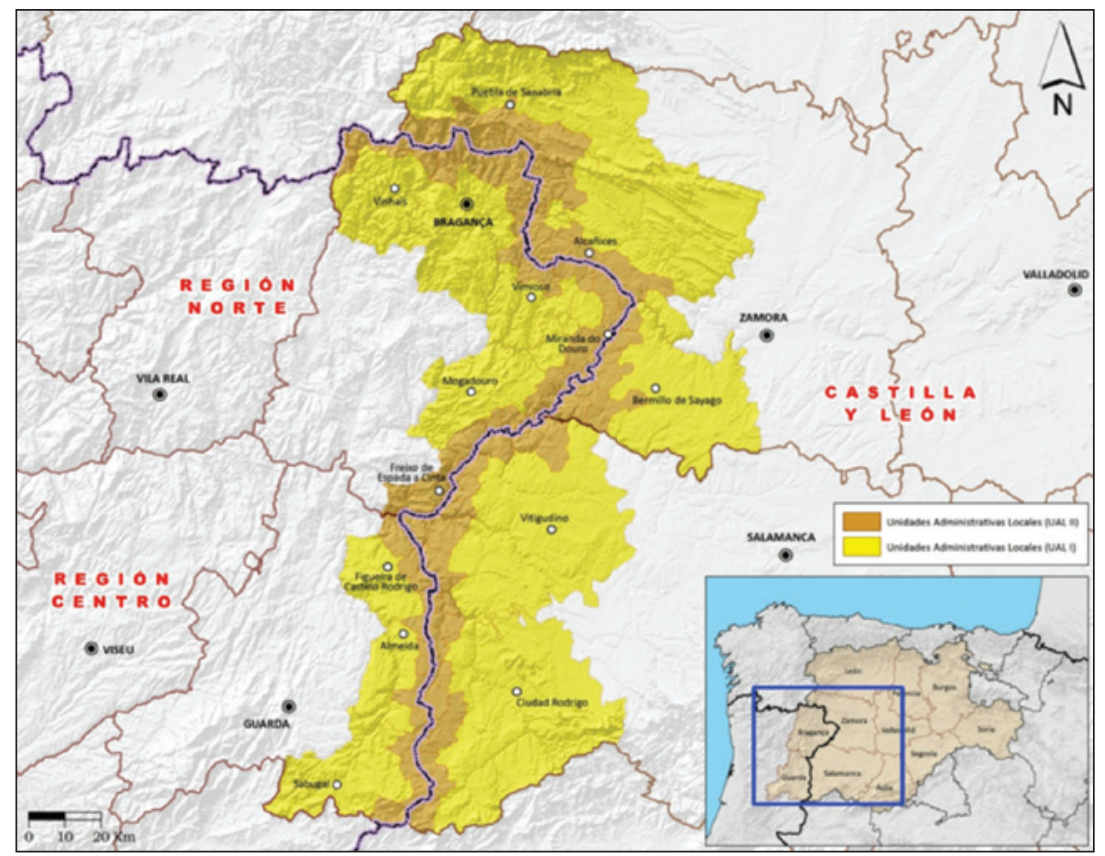

La localización de la «raya» en una margen del territorio nacional y en el borde occidental regional castellanoleonés ${ }^{3}$ introduce una cierta especificidad a este espacio que ha derivado en una divergencia social y económica en comparación con el resto peninsular. En primer lugar, la larga distancia existente entre la zona y los centros administrativos transmite una imagen de alejamiento y refuerza la idea de una ubicación en la «periferia de la periferia». En segundo lugar, la falta de continuidad territorial en algunos tramos de la línea de frontera por la presencia de la barrera o telón que forman los hondones fluviales reafirma la visión de un «espacio confinado» o un «finis terrae» (fin de la tierra). En tercer lugar, las desventajas de su situación marginal y los obstáculos del medio natural han condicionado el desarrollo socioeconómico, durante siglos dominado por una «economía

3 Cabero Diéguez, V. (2004). «Bordes y márgenes del territorio en Castilla y León: integración y cooperación», en: Clemente Cubillas, E.; Martín Jiménez, Ma . I. y Hortelano Mínguez, L. A. (Coord.): Monográfico Territorio y planificación, una aproximación a Castilla y León, Revista Economía y Finanzas de Castilla y León, n 9, pp. 79-95. 
de subsistencia» enmascarada por una «economía de contrabando» al margen de la legalidad. Por último, la pervivencia de diversos modos de vida adaptados a la dura vida rural y la ausencia de ciertos servicios básicos fueron suficientes motivos para incluir a esta zona en la categoría de «atrasados» y «deprimidos» como sinónimo de «subdesarrollo» ${ }^{4}$. En la actualidad, a la luz de una mirada renovada de la «frontera» se considera que el enclaustramiento del área y el estilo de vida de los habitantes rayanos han contribuido a la construcción de un patrimonio territorial diverso y frágil con grandes potencialidades a través de su puesta en valor para un uso alternativo de cara a la afluencia turística.

\section{LOS RECURSOS TURÍSTICOS DEL PATRIMONIO NATURAL Y CULTURAL}

Los acontecimientos del devenir histórico, la marcada personalidad geográfica y los usos y aprovechamientos de la «raya» han conformado un amplio y diverso patrimonio territorial que, en el umbral del siglo XXI, se erige en un eje de gran potencialidad para la atracción turística. Los elementos de este patrimonio territorial giran alrededor de la biodiversidad del medio físico, de la excelencia de los hitos monumentales y del significado simbólico de las manifestaciones populares. En el pasado periodo finisecular, desde muchas y variadas instancias se ha realizado un esfuerzo de recopilación y de clasificación de los potenciales recursos del patrimonio natural y cultural de la zona fronteriza con el objetivo de impulsar el uso turístico y de dinamizar de forma alternativa la economía local.

\subsection{Los elementos del medio natural: Espacios Naturales y Red Natura 2000}

El medio natural de la zona está marcado por las formas del relieve presididas por las sierras, el piedemonte, las fosas, las penillanuras y los profundos valles esculpidos por el río Duero y sus afluentes. Estas grandes unidades ambientales constituyen el hábitat de especies botánicas y faunísticas protegidas por la legislación europea, nacional y autonómica que han dado paso a la inclusión de amplias áreas en la Red de Espacios Naturales Protegidos (REN) y en la Red Natura 2000, bien como Zonas de Especial Protección para las Aves (ZEPAs) bien como Lugares de Interés Comunitario (LICs). En la actualidad, los espacios naturales ya declarados en la vertiente española son los Parques Naturales del «Lago de Sanabria y alrededores» y de «Arribes del Duero». A su vez, los espacios naturales de «El Rebollar» y de la «Sierra de la Culebra» comenzaron el procedimiento de protección en 1992 con el inicio de la elaboración del Plan de Ordenación de los Recursos Naturales (PORN) que aún está sin finalizar y, por tanto, no tienen asignada una figura concreta (ver Fig. 2). A modo de bisagra, en el lado portugués se encuentran refrendados los territorios de los Parques Naturales de «Montesinho» (74.100 ha) y del «Douro Internacional» (85.150 ha) y la Reserva Natural da «Serra da Malcata» (16.348 ha).

El primer espacio natural protegido dentro de la franja fronteriza fue el Parque Natural del «Lago de Sanabria y alrededores», declarado en 1978 y con una posterior ampliación en 1990 hasta las 22.345 ha de extensión. El perímetro del parque engloba los elementos

4 Luís Carandell Robuste y Eduardo Barrenechea, recorrieron la frontera en 1973, antes de la Revolución de los Claveles, para realizar un reportaje para el Diario Informaciones y, posteriormente, publicaron con este material el libro La raya de Portugal. La frontera del subdesarrollo para la editorial Cuadernos para el Diálogo. 
de la glaciación que dieron lugar a la formación geológica del Lago de Sanabria (lámina de agua de 347,6 ha), constituidos por las morrenas frontales y laterales, una riqueza botánica con más de 1.500 especies vegetales y una variedad de más de 190 vertebrados. En segundo lugar, en el año 2002 se reconoce el Parque Natural de «Arribes del Duero» con una superficie aproximada de 106.105 ha. Los cortados y farallones formados por el río Duero y sus afluentes constituyen el área ideal para la nidificación de especies como la cigüeña negra (Ciconia nigra), el alimoche (Neophron percnopterus) o el buitre leonado (Gyps fulvus). Por último, los espacios naturales de «El Rebollar» (50.040 ha) y de la «Sierra de la Culebra» (65.891 ha) se integraron en 1991 en la Red de Espacios Naturales de Castilla y León por su condición de zonas privilegiadas para especies de la fauna ibérica catalogadas «en peligro de extinción», como por ejemplo el Lince ibérico (Lynx pardinus).

Igualmente, la Consejería de Fomento y Medio Ambiente de la Junta de Castilla y León a partir de la Directiva Comunitaria 79/409/CEE, de 2 de abril (Directiva Aves) y de la Directiva 92/43/CEE, de 21 de mayo (Directiva Hábitats) ha incluido en el inventario de la Red Natura 2000 una amplia lista de áreas de la franja fronteriza, En concreto en la «raya», la administración europea ha reconocido nueve Zonas de Especial Protección para las Aves (ZEPAs) con el fin de asegurar la supervivencia y la reproducción de algunas especies de aves amenazadas, como por ejemplo, la cigüeña negra, el alimoche, el buitre leonado, el águila real, el águila perdicera o el milano real y, además, ha catalogado quince Lugares de Importancia Comunitaria (LICs) para garantizar el mantenimiento o, en su caso, el restablecimiento, en un estado de conservación favorable, de los tipos de hábitats naturales de interés comunitario y de los hábitats de las especies de interés comunitario. Por tanto, los espacios naturales a partir de la designación de las zonas y de los lugares de la Red Natura 2000 se encuentran cosidos unos con otros al funcionar alguno de estos tentáculos a modo de «corredores ecológicos». Esta maraña de manchas naturales cumple la doble función de conservación de los valores naturales y de mejora de la biodiversidad de especies y de hábitats, pero al mismo tiempo, constituye un motor de desarrollo socioeconómico al erigirse como recursos con gran potencialidad turística.

Esta riqueza natural asociada al buen hacer de la población a lo largo de la historia, animó a la Agrupación Europea de Cooperación Territorial «AECT ZASNET» ha presentar la candidatura ante la UNESCO de la «raya» como Reserva de la Biosfera Transfronteriza con la denominación «Meseta Ibérica», que fue aceptada el 9 de junio de 2015. El área seleccionada comprende 108 municipios españoles (79 de Zamora y 29 de Salamanca) y 17 concelhos de Portugal de las subcomarcas trasmontanas de Terra Quente y Terra Fria y Douro Superior. El proyecto «Meseta Ibérica» cuenta con la originalidad de la orientación transfronteriza de la propuesta (se extiende por un total de 1.504.915 hectáreas), así como, de la selección de una amplia zona para proteger y gestionar la gran biodiversidad con la que cuenta a partir de las características naturales y el patrimonio cultural. El objetivo general de la reserva es fomentar la cooperación transfronteriza con el fin de conservar el medio natural, impulsar el desarrollo socioeconómico sostenible y la calidad de vida de la población. La Reserva de la Biosfera integra los Parques Naturales del «Lago de Sanabria y alrededores», de «Arribes del Duero», de «Montesinho» y del «Douro Internacional», así como, la Reserva Natural «Lagunas de Villafáfila», el Espacio Natural «Sierra de la Culebra» y una amplia lista de espacios catalogados como zonas húmedas, microrreservas de flora, etc. 
Figura 2

ESPACIOS NATURALES Y RED NATURA 2000

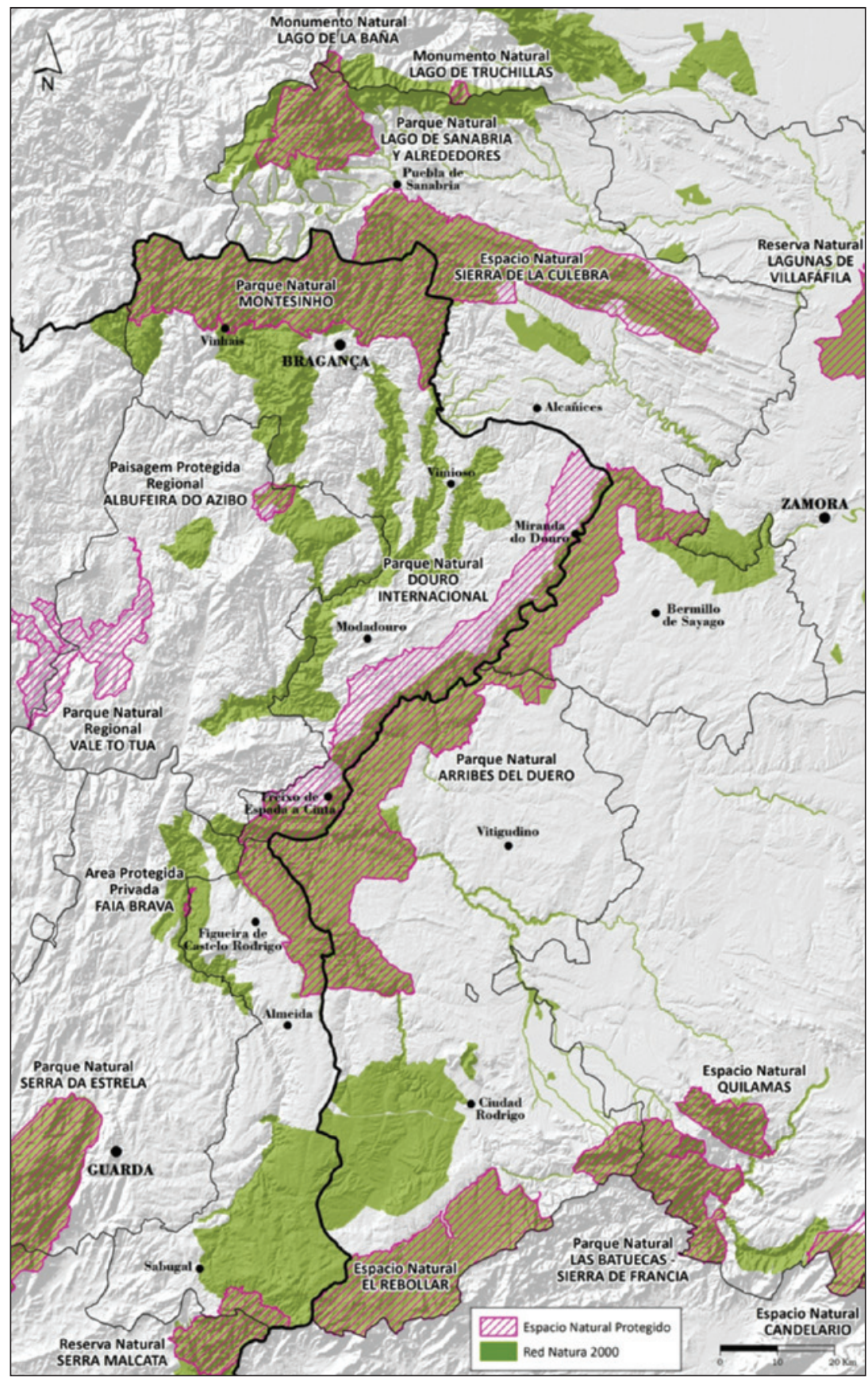

Cuadernos de Turismo, 36, (2015), 247-268 


\section{Fotografía 1}

GALENDE. PARQUE NATURAL DEL «LAGO DE SANABRIA Y ALREDEDORES»

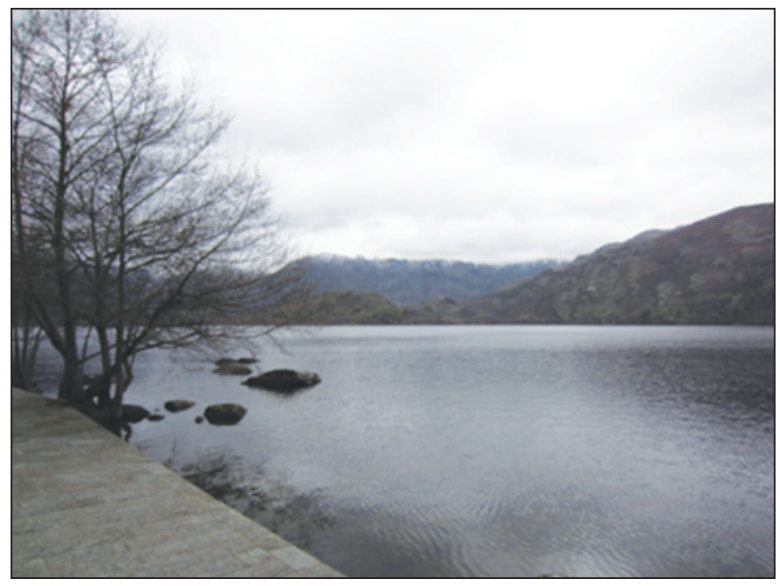

Fotografía 2

\section{ALDEADÁVILA DE LA RIBERA. PARQUE NATURAL DE «ARRIBES DEL DUERO}

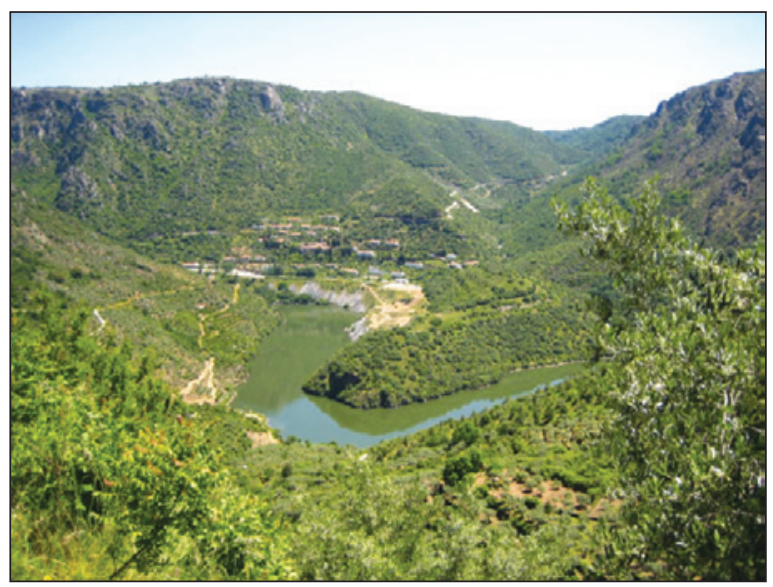

2.2. Los bienes del patrimonio cultural edificado: castillos, zonas arqueológicas y conjuntos etnológicos

La franja fronteriza está salpicada de hitos patrimoniales materiales de todo tipo, algunos incluidos en la Lista del Patrimonio de la Humanidad por la UNESCO y otros reconocidos por la administración con una protección genérica o con la asignación de alguna categoría de los Bienes de Interés Cultural (BIC), como herencia del paso de las diferentes culturas por este territorio (ver Fig. 3). La temprana ocupación de estas tierras por grupos 
prehistóricos ha dejado muestras de arte rupestre en las rocas de abrigos y de covachos. El yacimiento rupestre más sobresaliente es la Zona Arqueológica de la Estación Rupestre de «Siega Verde», que comprende los paneles del Paleolítico Superior situados en las riberas del Águeda a su paso por los municipios de Castillejo de Martín Viejo, Villar de Argañán y Villar de la Yegua, dentro de la lista del Patrimonio de la Humanidad de la UNESCO desde el 1 de agosto del 2010 como extensión del yacimiento portugués de Vale do Côa.

Los grupos étnicos sedentarios levantaron los parapetos y los campos de piedras hincadas para defensa de los castros y dedicaron extramuros una pequeña necrópolis destinada a los enterramientos funerarios. Posteriormente, los primitivos castros vetones presididos por un verraco u otra escultura zoomorfa fueron ocupados por los pueblos romano y visigodo que realizaron mejoras urbanas y dotaron a los recintos de templos cristianos. En la franja fronteriza, se encuentran numerosas estaciones arqueológicas de este tipo pero los mejores ejemplos son el Castro de Las Merchanas (Lumbrales y Bermellar) y el Castro de Yecla la Vieja o «El Castillo» (Yecla de Yeltes).

En otros momentos de la historia, la defensa de la línea fronteriza ha requerido de la presencia de tropas atrincheradas tras los sólidos muros de castillos y de fortalezas ${ }^{5}$. Las atalayas y cercas, con el paso del tiempo, terminaron con la incorporación de refuerzos defensivos e, incluso, se levantaron fuertes abaluartados en los siglos XVII-XVIII con el fin de proteger a los soldados de la artillería. Las obras de fortificación transformaron Ciudad Rodrigo, Puebla de Sanabria y San Felices de los Gallegos e impulsaron la construcción de las plazas abaluartadas en Aldea del Obispo con el «Real Fuerte de la Concepción», en Torregamones con el «Fuerte Nuevo», en Carbajales de Alba con el «El Fuerte» y en Puebla de Sanabria con el «Fuerte de San Carlos»6.

La presencia de los elementos defensivos son una constante a ambos lados de la divisoria fronteriza, bien de forma aislada o bien integrados en los conjuntos urbanos, como herencia de un pasado lleno de conflictos y que, en la actualidad, conforman un paisaje cultural con una fuerte carga histórica. Las tramas urbanas y las diversas tipologías de edificación generadas en la Edad Media, con modificaciones posteriores, se reconocen en los Conjuntos históricos de Ciudad Rodrigo, Fermoselle, Puebla de Sanabria, San Felices de los Gallegos y Villardeciervos. El inventario de Bienes de Interés Cultural, en la categoría de Monumentos, incluye una diversidad de tipologías encuadradas en la arquitectura religiosa (monasterios, conventos, santuarios, capillas e iglesias) y civil (casas consistoriales, palacios y casas nobles) y en las obras de ingeniería (puentes). Dentro de este catálogo, como muestra de una obra señera de la ingeniería ferroviaria sobresale la Línea Férrea «La Fuente de San Esteban-La Fregeneda» debido a las soluciones técnicas que se construyeron en el tramo de conexión con las tierras portuguesas para salvar el desnivel entre la penillanura y el encajamiento del río Águeda y Duero en el Puerto de Vega de Terrón. En los últimos diecisiete kilómetros, tras la Estación Internacional de La Fregeneda, se levantaron varios viaductos sobre los profundos valles de los afluentes del río Águeda y se horadaron en la roca veinte túneles.

5 Balado Pachón, A. y Escribano Velasco, C. (2011): Castillos de las Fronteras. Junta de Castilla y León. Consejería de Cultura y Turismo. Valladolid. 216 pp.

6 Larrén Izquierdo, H., Sánchez Cruz, P. J. y Marcos Contreras, G. J. (2010): Fortificaciones abaluartadas de la provincia de Zamora. Junta de Castilla y León. Consejería de Cultura y Turismo. Zamora. 63 pp. 
Figura 3

LOCALIZACIÓN DE LOS BIENES DE INTERÉS CULTURAL (BIC)

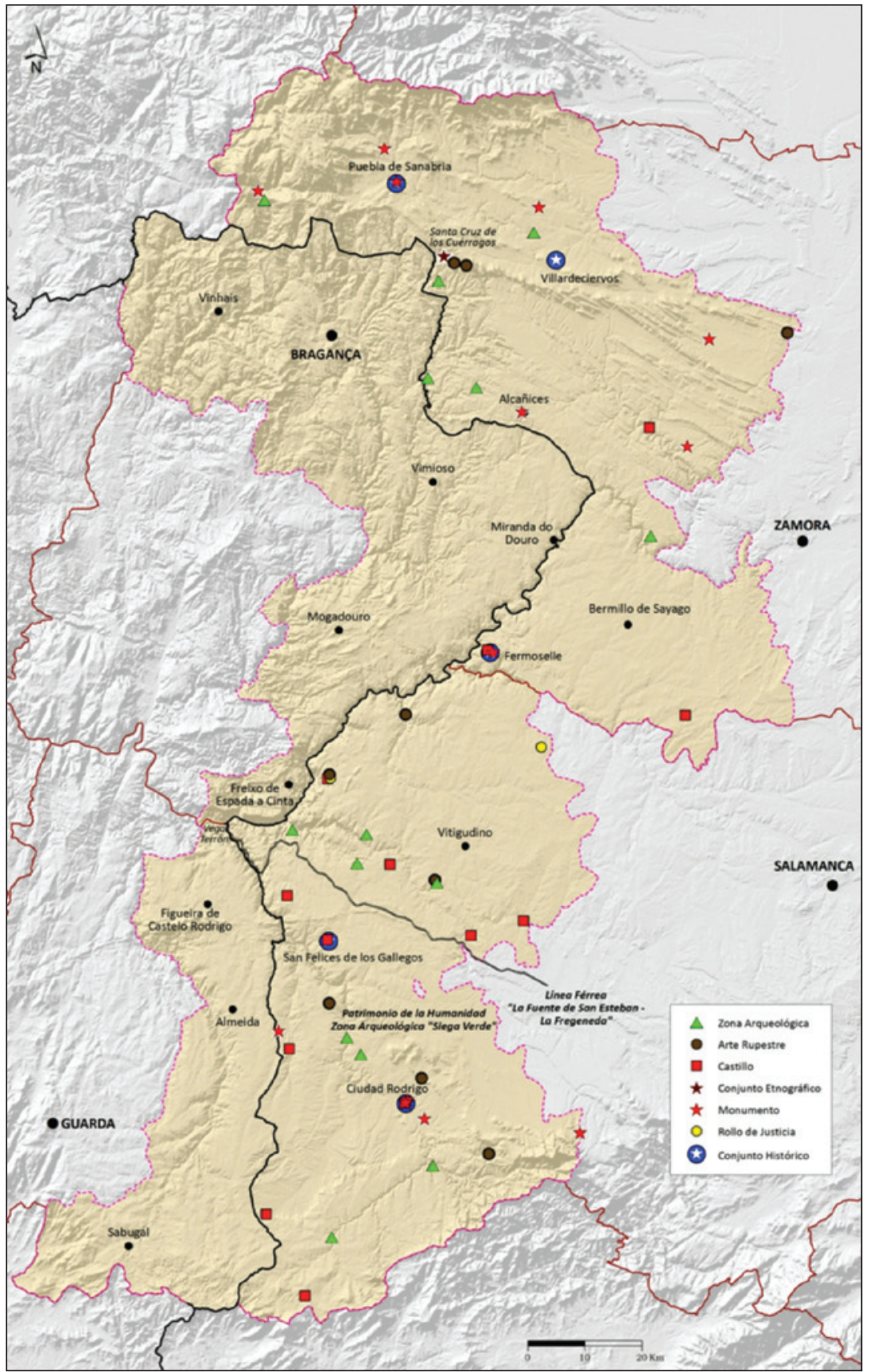

Cuadernos de Turismo, 36, (2015), 247-268 
También, en el marco de la normativa autonómica sobre Patrimonio Cultural, se ha incluido en la relación de bienes en la categoría de Conjunto Etnológico a la localidad fronteriza de Santa Cruz de los Cuérragos, en el término municipal de Manzanal de Arriba. El pequeño casco urbano constituye un ejemplo único de conservación integral de la arquitectura popular de la Sierra de la Culebra, adaptada a las condiciones naturales, usos, aprovechamientos tradicionales y materiales predominantes en esta zona de transición entre las comarcas de Aliste, de La Carballeda y de Sanabria.

Por último, en la raya existe un rosario de elementos del patrimonio cultural material que aunque no están catalogados como Bien de Interés Cultural reúnen todos los requisitos para formar parte de los bienes inventariados. En esta situación, se encuentra el «Puente Pino» o «Puente de Requejo» sobre el río Duero que une los municipios zamoranos de Villadepera y Pino del Oro. El puente que vincula las tierras de Sayago con las de Aliste fue inaugurado el 15 de septiembre de 1914 tras cinco años y medio de obras. El viaducto proyectado por el ingeniero José Eugenio Ribera e impulsado por Federico Requejo, como Director General de Obras Públicas, consta de un arco de 120 metros de luz con una altura de 90 metros donde apoya un tablero. Igualmente, en las comarcas rayanas existen numerosos puentes de piedra o «puentes de concejo» (de madera, de «gajas» o de «refaldos»), molinos harineros con sus zudas, corrales de pastores o «pariciones», pajares y otros edificios comunales (almazaras, hornos, fraguas, fuentes, norias, pontones, etc.) que han cumplido un papel trascendental en el modo de vida de este territorio y que se encuentran amenazadas de ruina por el abandono de las prácticas agropecuarias. En algunos casos, gracias al esfuerzo de ayuntamientos, vecinos y voluntarios han recuperado su estado original y conforman un elemento imprescindible para explicar la evolución del paisaje.

\subsection{Los atractivos del patrimonio cultural inmaterial: mascaradas de invierno, romerías, costumbres comunales y contrabando}

La inaccesibilidad durante años de la franja fronteriza ha permitido el mantenimiento de numerosas muestras del patrimonio cultural inmaterial que han pasado de generación en generación y, sin embargo, algunas prácticas populares han desaparecido por la despoblación y el envejecimiento de la población. En este caso, se encuentran varias costumbres comunales ${ }^{7}$ presentes en todas las comarcas rayanas y, que adquirían cierta particularidad, en las poblaciones fronterizas de Rihonor de Castilla del municipio de Pedralba de la Pradería y la freguesia de Rio de Onor de Portugal del concelho de Bragança. Igualmente, las variedades linguísticas de origen galaico-portugués y leonés se han perdido o se utilizan en muy pocos municipios, como por ejemplo, el habla del «rebollano» o «palra d'El Rebollal» en el extremo meridional de la comarca de Ciudad Rodrigo. Este subdialecto con influencias de la lengua astur-leonesa y gallego-portuguesa se encuentra próximo a las variedades dialectales que se hablan en la vertiente extremeña (el «mañego») y en las vecinas freguesias portuguesas (la «fala»).

7 Méndez Plaza, S. (1900): Costumbres comunales de Aliste. Imprenta del Asilo de Huérfanos del Sagrado Corazón de Jesús. Madrid. 77 pp. (Tercera reimpresión del Ayuntamiento de Riofrío y Semuret, 2002). 
Los ritos festivos constituyen las muestras más auténticas y comprometidas de la población local que, casi siempre, se acompañan de demostraciones musicales, de danzas y de exaltaciones gastronómicas. Las fiestas tienen diferentes motivaciones que engarzan celebraciones religiosas, reminiscencias paganas, ciclo agrario o recuerdos de hechos históricos significativos para la comunidad. En este grupo de recursos, emergen con fuerza las Fiestas declarada de Interés Turístico Nacional y Regional: Fiestas tradicionales del «Carnaval del Toro» (1965) y «La Charrada» (1991) en Ciudad Rodrigo, «El Noveno» (2005) en San Felices de los Gallegos, «Viernes Santo» (2011) en Bercianos de Aliste, «Romería de los Viriatos» (2010) en Fariza y «Los Carochos» (2002) en Riofrío de Aliste.

También, la Semana Santa de Bercianos de Aliste, del municipio de San Vicente de la Cabeza, ha conseguido el reconocimiento como Bien de Interés Cultural de carácter Inmaterial. La declaración como BIC (Inmaterial), incluye la protección material dentro del denominado «ámbito espacial y temporal» que viene determinado por el entorno urbano en el que tienen lugar las manifestaciones religiosas del Jueves y Viernes Santo, los espacios religiosos o públicos vinculados a la iglesia parroquial y su entorno (Templo de San Mamés y Plaza de la Pasión), el Calvario, el Vía Crucis (14 estaciones y 16 cruces) y el cementerio (el viejo y el nuevo).

En el calendario festivo, se pueden destacar un conjunto de citas por sus características y su especificidad: las mascaradas de invierno, los carnavales y las romerías transfronterizas. Las mascaradas de invierno comienzan a finales de año y se suceden hasta la festividad de los Reyes Magos, si bien, por diferentes causas algunas se trasladaron a los días del carnaval (Villanueva de Valrojo) y en contadas excepciones se celebran en verano (San Vicente de la Cabeza y Pobladura de Aliste). El significado de estas fiestas es muy variado según los investigadores, pero todas guardan una estrecha relación con la lucha del bien y del mal para ahuyentar los males que amenazan cosechas y animales, con ritos de purificación asociados con lo sagrado, y con la fertilidad de la tierra y de las personas y la petición del aguinaldo de los mozos por las casas de la localidad en Navidad, Año Nuevo y Reyes. En muy pocas ocasiones, estos festejos han pasado a los días de carnaval donde se puede hacer de todo amparados por las máscaras, incluido, mofarse del orden social. En otros rincones fronterizos, el toro preside los festejos del carnaval o los espectáculos taurinos se integran en el programa de las fiestas. A lo largo del mes de agosto, en las freguesias del concelho de Sabugal se celebran las «capeias raianas» con un marcado componente simbólico asociado al tránsito de la adolescencia a la mocedad y, en la actualidad, como nexo de unión de los emigrantes con sus raíces.

Otro grupo de fiestas, gira en torno a las romerías de primavera transfronterizas donde se produce una masiva afluencia de fieles hermanados por la devoción y donde se producen las actuaciones de danzas y de cánticos tradicionales acompañados por una banda de gaiteros. Las cuatro grandes citas rayanas, con actos religiosos y comerciales, son la «Virgen de la Luz» en Moveros y Constantim, la «Virgen de Fátima» en Villarino Manzanas y Petisqueira, «La Riberinha» en Quintanilha y San Martín del Pedroso y la «Virgen de la Salud» en Alcañices. Junto a estas expresiones religiosas, se pueden añadir la romería de «Los Viriatos» en Sayago, desde el casco urbano de Fariza hasta la ermita de la Virgen del Castillo, donde la patrona va acompañada de los pendones, pendonetas, cristos, cruces y estandartes de las localidades de Fariza, Palazuelo, Mámoles, Cozcurrita, Badilla, Arga- 
ñín, Tudera y Zafara; y la romería del Santuario de La Tuiza en Lubián donde se dan cita devotos llegados desde todos los pueblos de la Alta Sanabria, Galicia y Tras-os Montes.

Por último, en el área fronteriza se mantiene vivo el recuerdo nostálgico de la práctica del contrabando o del «descamino» ${ }^{8}$ que ha marcado a varias generaciones. Todavía, se conservan en la memoria colectiva, los pasos y los caminos por donde se trasegaba con los productos entre ambos lados de la frontera a escondidas de la mirada de los guardias y «guardiñas». Una actividad ilegal que permitió complementar las exiguas rentas de los habitantes rayanos a expensas de poner en riesgo su vida.

\section{Fotografía 3}

VILLARINO TRAS LA SIERRA (TRABAZOS). LOS ZAMARRONES, LOS CABALLICOS Y EL PAJARITO (26 DE DICIEMBRE)

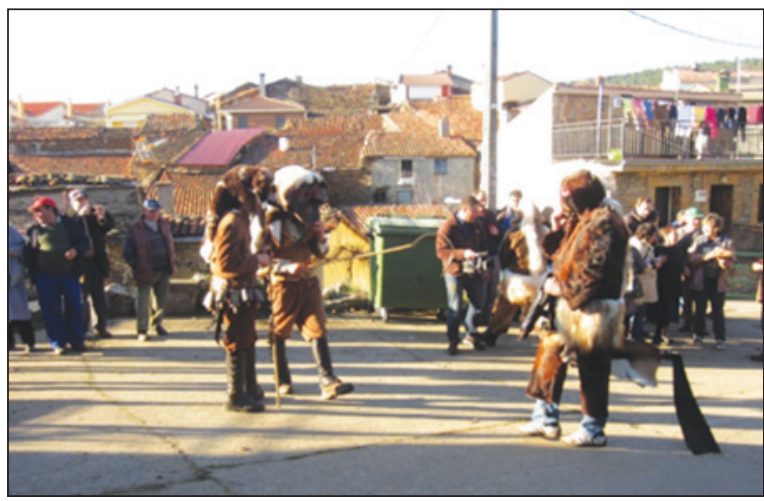

Fotografía 4

SAN FELICES DE LOS GALLEGOS. ENCIERRO DE LA FIESTA «EL NOVENO» (11 DE MAYO)

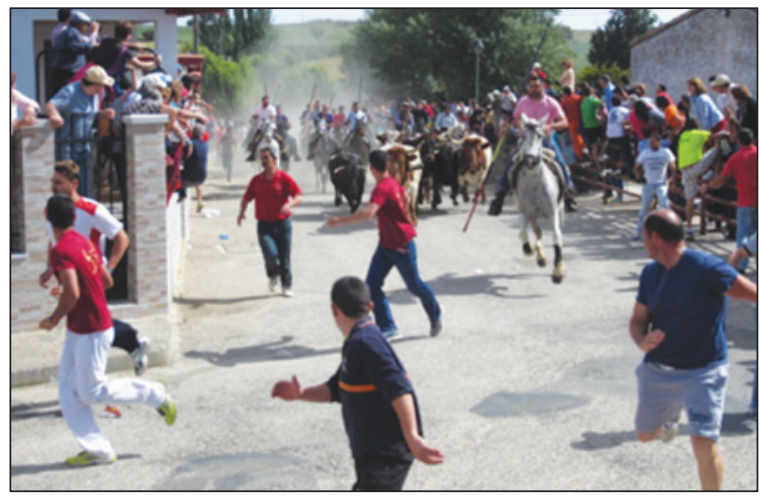

8 Cruz-Sagredo García, J. D. (2010): Contrabandistas somos y en el descamino nos encontraremos. Gabinete de Iniciativas Transfronterizas, Valladolid, Junta de Castilla y León. 


\section{LOS MICROPRODUCTOS Y PRODUCTOS TURÍSTICOS EN EL MARCO DE LAS MODALIDADES Y SEGMENTOS}

El patrimonio territorial heredado condiciona la apuesta, tanto de las administraciones públicas como del sector privado, por unas determinadas modalidades turísticas centradas en el ecoturismo en los espacios naturales protegidos, las acciones de turismo de naturaleza, las propuestas de turismo cultural y las actividades de turismo activo (ver tabla 1). Dentro de cada grupo de modalidades turísticas, se ofertan una serie de segmentos a raíz de las demandas sociales y de la aparición de nuevas tendencias innovadoras de ocio activo. En este marco, el turismo en la «raya» se ha reinventado al complementar las tipologías tradicionales, basadas en la contemplación de los grandes escenarios paisajísticos y pasar la frontera para comprar productos a precios más baratos o comer de forma abundante, con la puesta en valor de recursos hasta el momento inutilizados. La llegada de los fondos europeos, de la mano de los programas de desarrollo rural y de cooperación transfronteriza, ha posibilitado la recuperación y la adaptación de los recursos del medio natural y del patrimonio cultural. En este contexto, las instituciones y los empresarios privados presentan en el mercado diversos productos y «microproductos» con el objeto de combatir la estacionalización turística y contribuir a incrementar la estancia media y el grado de ocupación de los establecimientos hoteleros y extrahoteleros de la «raya».

Tabla 1

MODALIDADES Y SEGMENTOS DE TURISMO EN LA «RAYA»

\begin{tabular}{|c|c|}
\hline MODALIDADES & TIPOS/SEGMENTOS DE TURISMO \\
\hline \multirow{6}{*}{$\begin{array}{l}\text { ECOTURISMO } \\
\text { Y TURISMO DE } \\
\text { NATURALEZA }\end{array}$} & Red de Espacios Naturales \\
\hline & Turismo geológico o «geoturismo» \\
\hline & Turismo de salud y termalismo \\
\hline & Turismo ornitológico \\
\hline & Turismo de observación de fauna: avistamiento de lobos y «berrea» de los ciervos \\
\hline & Turismo fluvial \\
\hline \multirow{8}{*}{$\begin{array}{c}\text { TURISMO } \\
\text { CULTURAL }\end{array}$} & Turismo monumental o visitas a monumentos \\
\hline & Arqueoturismo \\
\hline & Turismo minero \\
\hline & Turismo lingüístico y literario \\
\hline & Turismo religioso \\
\hline & Fiestas de Interés Turístico y populares \\
\hline & Turismo micológico o Micoturismo \\
\hline & Gastronómico - Enogastronómico y Oleoturismo \\
\hline \multirow{4}{*}{$\begin{array}{c}\text { TURISMO } \\
\text { ACTIVO }\end{array}$} & Actividades terrestres: Senderismo, Centros BTT (Bicicleta Todo Terreno) \\
\hline & Actividades acuáticas: recorridos en barco \\
\hline & Actividades con animales: paseos en burro \\
\hline & Actividades mixtas: miltiaventura \\
\hline
\end{tabular}

Fuente: Junta de Castilla y León. Consejería de Cultura y Turismo. 


\subsection{Las prácticas de ecoturismo en espacios naturales protegidos y las acciones de turismo de naturaleza}

La oferta turística en los Espacios Naturales de la «raya»se genera a partir de las Casas del Parque abiertas al público en los Parques Naturales del «Lago de Sanabria y alrededores» («San Martín de Castañeda» y «Lago de Sanabria y alrededores» en Galende) y en «Arribes del Duero» («Convento de San Francisco» en Fermoselle y «El Torreón de Sobradillo»). Estas instalaciones son el primer referente para conocer los valores y la organización territorial para, a partir de esta información, adentrarse por los senderos homologados, con sus miradores, y utilizar las áreas de uso público. La gestión de los espacios naturales ha conllevado la catalogación de puntos de interés geológico, de árboles singulares, etc. y la recuperación de bienes del patrimonio etnográfico, así como, la colocación de paneles interpretativos del paisaje.

En relación a los productos de «turismo de naturaleza», las posibilidades de aprovechamiento de los recursos naturales son más amplias. En primer lugar, las singulares formaciones geológicas y geomorfológicas de la zona abren un campo novedoso desde el punto de vista científico y pedagógico para grupos de escolares y universitarios. El incipiente «turismo geológico» o «geoturismo» encuentra en las áreas del Lago de Sanabria y de Arribes del Duero un laboratorio para poner en práctica los conocimientos adquiridos en las aulas. Estas salidas al campo de estudiantes, han encaminado a los responsables institucionales a proponer en la frontera un Geoparque transfronterizo auspiciado por la UNESCO como fórmula de gestión, de conservación y de desarrollo sostenible.

En segundo lugar, desde los tiempos de los romanos se conocen y aprovechan las características terapéuticas de algunos manantiales diseminados por los municipios rayanos. En los siglos XVIII y XIX, estas aguas minero-medicinales se adaptaron a las exigencias de la demanda social en balnearios para el tratamiento de distintas dolencias -enfermedades de la piel y afecciones del riñón, digestivas y reumáticas- en relación con las propiedades sulfuradas, bicarbonatadas, clorurado sódicas y fluoradas de sus aguas. Hoy en día, con un renovado enfoque surge el «turismo de salud»y el «termalismo» con la recuperación de estas antiguas casas de baño en Almeida de Sayago y Calabor.

En tercer lugar, el número de aficionados al estudio, identificación y avistamiento de aves (o «birding») crece día a día en Europa y en España e, incluso, sus miembros («observadores de aves» o «birdwatching») están dispuestos a recorrer grandes distancias con el fin de ver una especie en su hábitat. Por este motivo, se ha diseñado un programa de «turismo ornitológico» en las comarcas de Sayago y Vitigudino de la mano del proyecto de «Turismo Rural de Interior y Ornitología» (TRINO) y, con el patrocinio, de la Fundación Patrimonio Natural de Castilla y León. Las acciones del proyecto tratan de hacer partícipes a los agentes sociales y a los empresarios de alojamientos de turismo rural a través de cursos de formación y la dotación de material específico en los establecimientos. Junto a las salidas ornitológicas, han surgido con fuerza colectivos y empresas que ofrecen recorridos por la Sierra de la Culebra y el Lago de Sanabria con el fin de observar lobos ibéricos (Canis lupus signatus) en libertad mediante el uso de 
prismáticos, telescopios y cámaras fotográficas. La alta concentración de manadas de lobos y su relación histórica con los habitantes de la zona se han erigido en un potente atractivo que la administración regional pretende encauzar con el «Centro de Interpretación del Lobo Ibérico», localizado en las proximidades de Robledo, dentro del término municipal de Puebla de Sanabria. En un periodo muy concreto de la estación vernal (desde finales del mes de septiembre y hasta principios de noviembre), en los espacios naturales del Lago de Sanabria, la Sierra de la Culebra y El Rebollar existe la posibilidad de salir al alba o a las horas del crepúsculo acompañados por un guía a observar la «berrea» o el celo de los ciervos (Cervus elaphus).

Por último, la riqueza de cursos fluviales que discurren por parajes recónditos y de manchas de agua con una alta biodiversidad ha animado a instituciones públicas y a particulares a presentar productos de turismo fluvial. La oferta de paseos en barco se concentra en el cañón del río Duero con los recorridos que realizan las empresas «Crucero Ambiental de Arribes del Duero» por el Embalse de Miranda do Douro, «Naturisnor-Turismo da Natureza do Nordeste» por el Embalse de Bemposta, «El Corazón de las Arribes» por el Embalse de Aldeadávila de la Ribera y la «Sociedad Transfronteriza Congida-La Barca» por el Embalse de Saucelle y, además, hay que añadir los paseos del Crucero Ambiental por el Parque Natural del Lago de Sanabria.

\subsection{Las propuestas de turismo cultural}

Las propuestas de turismo cultural encuentran soporte en la amplia lista de recursos patrimoniales, tanto de carácter material como inmaterial, que con el transcurrir del tiempo muchos habían caído en el desuso y en el olvido. Las intervenciones públicas han tratado de poner en valor estos avales mediante un uso cultural y turístico alternativo a su función tradicional. El tratamiento de los entornos de los cascos urbanos, incluidos los conjuntos históricos declarados de Alcañices, Ciudad Rodrigo, Fermoselle, Puebla de Sanabria, San Felices de los Gallegos y Villardeciervos, permiten un flujo de visitantes atraídos por el turismo monumental. En este redescubrimiento artístico-monumental, hay que incluir a todos los Bienes de Interés Cultural (BIC) en sus diferentes categorías y otros inmuebles merecedores de reconocimiento que arrastran a los turistas.

Uno de los productos más arraigados en el pasado histórico y en los hitos monumentales de la frontera es la «Ruta de Fortificaciones de Frontera. Punto de Encuentro». El itinerario se articula a través del Centro de Interpretación de Ciudad Rodrigo (Cuerpos de Guardia del Registro y de San Pelayo), el Aula Arqueológica de la Estación Rupestre de Siega Verde, el Aula Histórica del Real Fuerte de la Concepción en Aldea del Obispo, el Castillo de San Felices de los Gallegos y el Aula Arqueológica y el Castro de «Yecla la Vieja» en Yecla de Yeltes. Este proyecto surgió con un enfoque transfronterizo, en el marco de las iniciativas comunitarias de cooperación, pero la falta de coordinación dio pie a una propuesta distinta en el lado luso al englobar la «Rota das Aldeias Históricas de Portugal» un mayor número de intervenciones con una visión más integral del desarrollo. 
Los productos de arqueoturismo tienen una gran aceptación, sobre todo, las visitas guiadas al Aula Arqueológica y al conjunto de paneles de la Estación de Arte Rupestre de Siega Verde. Este yacimiento arqueológico, distribuido a lo largo de la margen izquierda del río Águeda, congrega en torno a los grabados del Paleolítico Superior a familias y grupos de escolares. Otra de las propuestas arqueológicas de éxito, impulsado por la Diputación Provincial bajo la marca «Territorio Vetón», es la visita a los castros de «Las Merchanas» en Lumbrales y de «Yecla la Vieja» o «Lugar Viejo» en Yecla de Yeltes a partir de los respectivos Centros de Recepción de Visitantes.

La riqueza de minerales y de recursos geológicos en el subsuelo de la zona ya era conocida desde tiempos de los romanos y, su explotación, ha generado huecos y huellas susceptibles de aprovechamiento turístico. Por esta razón, varios consistorios han tomado la iniciativa de acometer acciones de revalorización de los restos mineros del oro y del wolframio y, por ejemplo, encontramos el Museo de Mineralogía en Barruecopardo, las galerías «Pozo Hondo» y «Asentada de Morales» de la «Mina Salmantina» en Navasfrías y los senderos interpretativos en Pino del Oro y Villardiegua de la Ribera.

Al amparo de la devoción de la población local y de la plasticidad de algunos de los actos religiosos que se celebran en la zona fronteriza ha renacido un «turismo religioso» alrededor de las celebraciones sagradas y de las romerías. En otras ocasiones, la carga estética de las festividades y la originalidad de los ritos llama a un «turismo de fiestas» atraído por la cultura popular rural. En este apartado, no hay que dejar de citar a las corrientes de visitantes que se desplazan a la zona para vivir las diferentes variedades de espectáculos taurinos.

Finalmente, este ámbito territorial se asocia con una buena oferta culinaria e, incluso, genera desplazamientos para degustar platos típicos a base de productos agropecuarios locales y cinegéticos. La transmisión de las recetas de generación en generación ha propiciado un «turismo gastronómico» específico de cada comarca. Además, las selectas cartas se han ampliado gracias a la cuidada incorporación de nuevos platos de productos infravalorados hasta fechas muy recientes que han permitido desarrollar nuevas tipologías turísticas, por ejemplo, la enogastronomía, el oleoturismo o el turismo micológico o micoturismo. La producción local de vinos de calidad, de aceites de variedades autóctonas y de setas y de hongos abre un novedoso campo de posibilidades en las numerosas opciones que tiene la gastronomía (educación, manejo, promoción, comercialización, etc.).

\subsection{Las actividades de turismo activo}

En los últimos años, han surgido una serie de iniciativas empresariales de impulso de actividades de turismo activo ligadas al territorio y complementarias de la extensa red de alojamientos hoteleros y extrahoteleros. Según la clasificación regional, podemos identificar en la «raya» las siguiente actividades de turismo activo: terrestres de superficie (senderismo, recorridos a pie de corta distancia, trekking, recorridos a pie de larga duración y distancia, bicicleta todo terreno -BTT-, mountain bike, paintball, tiro con arco y orientación), acuáticas (piragüismo, canoa, kayak, hidropedales y vela), con 
animales (turismo ecuestre y paseos en burro) o mixtas (parques de aventura con cuerdas o cables, rapel, tirolina y multiactividad). Según el registro de empresas de turismo activo, existen 16 empadronadas en el área fronteriza que ofrecen estas actividades, aunque algunas más, con sede en otros municipios y concelhos operan en la zona.

En el grupo de las propuestas terrestres destaca el senderismo gracias a la señalización y homologación de los senderos de Gran Recorrido (GR), de Pequeño Recorrido (PR) y Senderos Locales (SL) acometidos por la Junta de Castilla y León, las Diputaciones Provinciales, los Ayuntamientos, las Mancomunidades de municipios y las Asociaciones. Como máxima expresión de estos recorridos, se pueden citar los Senderos de Gran Recorrido «GR-14» («Senda del Duero»), «GR-14.1» («Senda del Águeda»), «GR-84» («Montaña de Sanabria»), «GR-187» («Cañada Real de Extremadura») y «GR188» («Ruta de la Sierra de Gata»), que vertebran y cohesionan zonas de las comarcas fronterizas. Incluso, la Diputación Provincial de Salamanca dentro del Plan de Dinamización del Producto Turístico «Zona Sur de las Arribes del Duero» ha acometido unas acciones para crear la «Red de Senderos de la Frontera» y la Red de Miradores «Paisajes de Las Arribes». Por otro lado, con el propósito de crear nuevos productos, la propia Diputación Provincial de Salamanca, a través del reseñado Plan de Dinamización, y los Grupos de Acción Local ADATA y ADISAC-La Voz a partir del proyecto de cooperación «Espacios-Travesía BTT», han generado una serie de centros y de rutas para bicicletas de montaña homologadas por la «International Mountain Bicycling Association». Por tanto, las administraciones públicas centran sus esfuerzos en las actividades terrestres, con infraestructuras de ocio, y deja a los emprendedores las actividades acuáticas, con animales y de multiactividad.

\section{Fotografía 5 \\ CORPORARIO (ALDEADÁVILA DE LA RIBERA). TURISMO FLUVIAL DESDE LA PLAYA DEL ROSTRO}

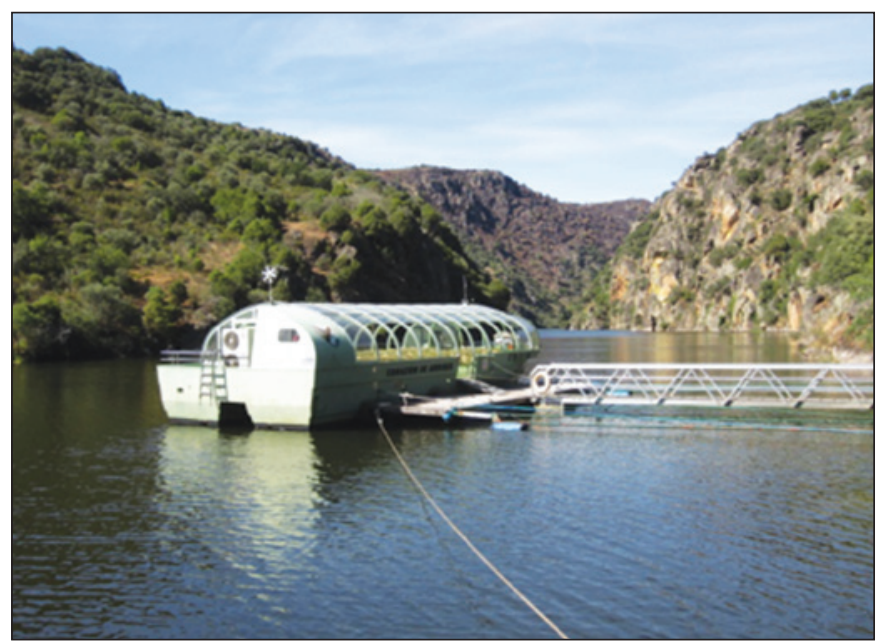




\section{Fotografía 6 \\ SAN FELICES DE LOS GALLEGOS. TURISMO ACTIVO BASADO EN MULTIAVENTURA}

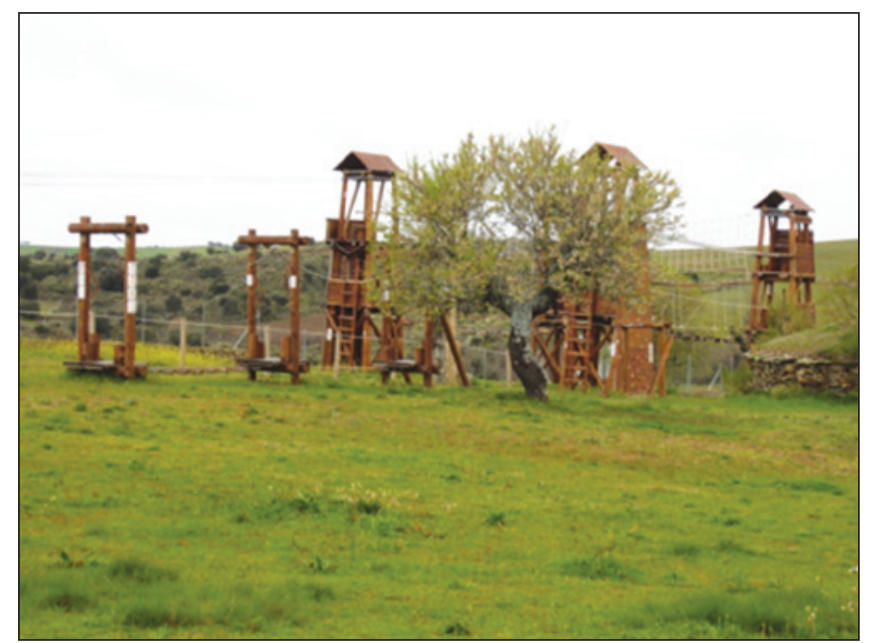

\section{CONCLUSIONES: EL «TURISMO DE FRONTERA» EN EL HORIZONTE 2020}

La línea de frontera de Castilla y León con las Regiones del Centro y del Norte de Portugal se extiende a lo largo de 349 kilómetros, entre el mojón situado en el municipio zamorano de Hermisende y el hito localizado en la Sierra de las Mezas en Navasfrías de la provincia salmantina, que se amoldan a los cordales cimeros y a los resaltes de la penillanura (denominados estos tramos como «raya seca») y a los cauces fluviales o «raya húmeda». Desde el punto de vista administrativo, la franja fronteriza próxima al límite fronterizo comprende 37 términos municipales del lado español y 54 freguesías de la vertiente portuguesa y, por tanto, la franja transfronteriza a escala local («Unidades Administrativas Locales» UAL II) engloba 91 entidades con 4.060,31 km². Esta referencia territorial, en cuanto a las actividades turísticas, se ve desbordada hasta la escala supramunicipal («Unidades Administrativas Locales» UAL I) y, por tanto, el flujo de visitantes se deja notar en las comarcas agrarias de Vitigudino y de Ciudad Rodrigo, en Salamanca, y en las de Sanabria, Aliste y Sayago, en Zamora. Las comarcas españolas, junto a los concelhos portugueses de Vinhais, Bragança, Vimioso, Miranda do Douro, Mogadouro, Freixo de Espada à Cinta, Figueira de Castelo Rodrigo, Almeida y Sabugal, conforman un «espacio transfronterizo» de 15.901,25 $\mathrm{km}^{2}$ de superficie.

Esta zona adolece de una serie de desventajas en el ámbito social, económico y territorial derivadas de su localización periférica a escala nacional y regional y por los estrangulamientos internos. La lejanía de la frontera de los centros de decisión política y económica y la transformación de las infraestructuras de comunicación exterior en vías rápidas ha consagrado una visión de la «raya» como espacio de borde y de tránsito entre 
ambos países. A esta mirada negativa, hay que sumar la realidad de falta de conexión transfronteriza y de desvertebración interior debido a las exigentes condiciones del medio físico que provocan problemas de accesibilidad, de alargamiento de los tiempos de los recorridos y de continuidad territorial, y los convierte en verdaderos «fondos de saco». También, los obstáculos naturales han puesto trabas al normal desarrollo social y económico de la frontera que terminó con la salida de la población joven y la quiebra del modelo basado en las actividades agropecuarias y silvícolas. Las fracturas sociales, económicas y territoriales provocadas por el éxodo rural son evidentes y, para mantener la población e impulsar la economía, a raíz de las orientaciones europeas y en el marco del desarrollo local se ha aptado por la puesta en valor de los recursos del patrimonio natural y cultural para el uso turístico.

Los recursos del patrimonio natural están relacionados con los elementos geológicos, los valores botánicos y faunísticos y, de forma integral, en las diversas unidades de paisaje. La conservación y gestión de todos los valores ha propiciado la declaración de amplias áreas como espacios naturales protegidos: los Parques Naturales del «Lago de Sanabria y alrededores» y de «Arribes del Duero» y los espacios naturales «El Rebollar» y de la «Sierra de la Culebra», en la parte española, y los Parques Naturales de «Montesinho» y del «Douro Internacional» y de la Reserva Natural da «Serra da Malcata» en el lado portugués. En paralelo, las administraciones han catalogado 9 Zonas de Especial Protección para las Aves (ZEPAs) y 15 Lugares de Interés Comunitario (LICs) en virtud de las directivas comunitarias que regulan la Red Natura 2000. Por último, a la red de espacios naturales protegidos y a los lugares y hábitats de la Red Natura 2000 se suman un rosario de zonas húmedas, montes, vías pecuarias y microrreservas de flora. Ante tanta riqueza natural, la Agrupación Europea de Cooperación Territorial «AECT ZASNET» ha conseguido la declaración como Reserva de la Biosfera de una amplia área transfronteriza bajo la denominación de «Meseta Ibérica».

En cuanto a los recursos del patrimonio cultural, podemos diferenciar los bienes del patrimonio material centrados en los yacimientos arqueológicos, los recintos defensivos y los conjuntos etnográficos, mientras que, los valores del patrimonio inmaterial congregan ritos festivos, tradiciones y actividades populares. Dentro del patrimonio cultural material, destaca la Zona Arqueológica de la Estación Rupestre de «Siega Verde» al incluirse el 1 de agosto del 2010 en la Lista del Patrimonio de la Humanidad de la UNESCO como una extensión del yacimiento de Vale do Côa en Portugal. En el inventario de Bienes de Interés Cultural, cuentan los municipios rayanos con una serie de herencias registradas en la protección genérica de castillo y en las categorías de zona arqueológica, monumento, conjunto histórico y conjunto etnológico.

Los bienes del patrimonio inmaterial se circunscriben a una serie de manifestaciones populares, algunas de las cuales han caído en el olvido por la despoblación y el envejecimiento, que se centran en el mantenimiento de las fiestas acompañadas de danzas y de cánticos. En el imaginario colectivo pervive aún el recuerdo nostálgico de las costumbres comunales de la vida cotidiana y las prácticas del contrabando ya desaparecidas.

Los recursos del medio natural y del patrimonio cultural material e inmaterial de la «raya» sustentan las diversas modalidades turísticas y, a su vez, en estas variedades encontramos segmentos distintos o tipologías de ocio. En base a las tipologías turísticas, 
las instituciones y los emprendedores ofrecen en los mercados una serie de productos y «microproductos» con el fin de alcanzar el desarrollo económico del área mediante la desestacionalización de la demanda y contribuir a mejorar la estancia media en los alojamientos. La práctica del ecoturismo o turismo en espacios naturales protegidos se encuentra mediatizada por la gestión de los responsables del espacio que, a partir de las Casas del Parque, recomiendan recorridos por senderos señalizados y actividades programadas de temporada de educación ambiental. Las posibilidades del turismo de naturaleza son mayores al existir infraestructuras y empresas que proponen acciones en el marco del turismo geológico o «geoturismo», del turismo de salud y termalismo, del turismo ornitológico, del turismo de observación de fauna (avistamiento de lobos y «berrea» de los ciervos) y del turismo fluvial. Igualmente, se han creado productos en torno al turismo monumental o visitas a monumentos, al arqueoturismo, al turismo lingüístico y literario, al turismo religioso y festivo, al turismo micológico o micoturismo y al gastronómico (enogastronómico y oleoturismo). Por último, las empresas de turismo activo trabajan en las siguientes actividades: terrestres (senderismo, rutas BTT, etc.), acuáticas (recorridos en barco y alquiler de embarcaciones), con animales (paseos en burro zamorano-leonés y caballo) y de multiaventura. En el conjunto de los segmentos turísticos, la oferta que podríamos definir y catalogar como emergente e innovadora estaría asociada con el turismo ornitológico, la observación de fauna salvaje, el micoturismo y los centros y rutas BTT (Bicicleta de Montaña o Bicicleta Todo Terreno).

Finalmente, se ha constatado que la «raya» es un territorio en «desventaja geográfica» pero con grandes recursos que por sí solos pueden generar atracción de visitantes y pernoctaciones; sin embargo, tras arduos años de trabajo aún hoy no se puede hablar de la frontera como un «destino turístico» con una marca específica de «turismo de frontera». Los turistas se acercan a la frontera por el conglomerado de productos y «microproductos» enmarcados en segmentos turísticos que se han generado de forma espontánea. De cara al futuro, con el horizonte en el año 2020, se imponen algunas acciones de coordinación y de planificación estratégica intracomarcal y transfronteriza para conseguir un efectivo «turismo de frontera».

\section{BIBLIOGRAFÍA}

AZEVEDO, J. (Ed.) (1998): Entre Duas Margens. Douro Internacional. Mirandela, Tipografía Guerra.

CABERO DIÉGUEZ, V. y PLAZA GUTIÉRREZ, J. I. (1987): «El sector fronterizo de Salamanca y Zamora con Portugal. Tradición y modernización», en Encuentros/ Encontros de Ajuda. Olivenza, 18-20 de octubre de 1985. Actas, Ponencias y Comunicaciones. Badajoz, Servicio de Publicaciones de la Excma. Diputación Provincial de Badajoz, pp. 247-275.

CABERO DIÉGUEZ, V. (Coord.) (1994): Contribución para la definición de una estrategia de intervención y la promoción de iniciativas comunes. Cooperación entre la Región Centro (Portugal) y las Regiones de Castilla y León y Extremadura (España). Salamanca, Diputación de Salamanca y Universidad de Salamanca.

CABERO DIÉGUEZ, V. (1997): «Portugal y España: una mirada geográfica a las relaciones ibéricas», Boletín de la Asociación de Geógrafos Españoles, n 25, pp. 3-13. 
CABERO DIÉGUEZ, V. (2004): Iberismo y Cooperação. Passado e futuro da Península Ibérica. Guarda, Centro de Estudos Ibéricos, Câmara Municipal de Guarda.

CARAMELO, S. (2007): União Europeia, Fronteira e territorio. Guarda, Centro de Estudos Ibéricos. Câmara Municipal de Guarda.

HORTELANO MÍNGUEZ, L.A. (2000): «Proyectos financiados por los fondos estructurales en el medio rural de Castilla y León», Revista de Economía y Finanzas de Castilla y León, $\mathrm{n}^{\circ}$ 4, pp.131-152.

HORTELANO MÍNGUEZ, L.A. (2004): «La conservación de la naturaleza, componente básico de la ordenación del territorio de Castilla y León», Revista de Economía y Finanzas de Castilla y León, $\mathrm{n}^{\circ}$ 9, pp.123-145.

HORTELANO MÍNGUEZ, L. A. (2006): Análisis territorial e inventario de recursos de la raya hispano-lusa: comarca de Ciudad Rodrigo y Tierras de Riba-Côa. Organismo Autónomo de Empleo y Desarrollo Rural. Diputación de Salamanca. Salamanca, $139 \mathrm{pp}$.

HORTELANO MÍNGUEZ, L.A. (2007): «Revitalización y promoción de la «Ruta del Duero»: las iniciativas de excelencia y las propuestas innovadoras», Cuadernos de Turismo, $\mathrm{n}^{\mathrm{o}}$ 20, pp. 103-130.

HORTELANO MÍNGUEZ, L.A. (Coord.) (2008): Atlas de la raya hispano-lusa: Salamanca-Beira Interior Norte/Alto Douro. Salamanca, Diputación Provincial de Salamanca. Organismo Autónomo de Empleo y Desarrollo Rural.

HORTELANO MÍNGUEZ, L.A. (Coord.) (2009): Atlas de la raya hispano-lusa: Zamoral Trás-os-Montes. Salamanca, Diputación Provincial de Zamora.

HORTELANO MÍNGUEZ, L.A. (2013): «Las actividades turísticas en la zona fronteriza de Castilla y León con las regiones Norte y Centro de Portugal: un espacio interior y de baja densidad poblacional», en Melgosa Arcos, F.J. (Coord.) Turismo de Interior. Planificación, comercialización y experiencias. Madrid, Editorial Pirámide, pp. 139-157.

HORTELANO MÍNGUEZ, L.A. (2013): «El turismo de la Raya Ibérica en la Cooperación Transfronteriza de primera generación (1992-2013): el caso de Castilla y León», en Campesino Fernández, A.J. (Coord.): Turismo de Frontera (I), Vigo, Rede Ibérica de Entidades Transfronteiriças (RIET), pp. 131-139.

HORTELANO MÍNGUEZ, L.A. (2014): «Recursos naturales y turismo en la Raya castellano-leonesa», en Campesino Fernández, A. J. (Coord.). Turismo de frontera (II). Oferta y demanda turística en la Raya ibérica. Cáceres, CopeGraF, s.l., p. 11-32. HORTELANO MÍNGUEZ, L.A. (2014): «Los productos turísticos en la «franja fronteriza» de Castilla y León con Portugal: la adaptación de los recursos y la interpretación territorial», en Campesino Fernández, A. J. y Jurado Almonte, J. M. (Dir.). Turismo de frontera (III). Productos turísticos de la Raya Ibérica. Ediciones Universidad de Huelva. Huelva, pp. 73-97.

MARTÍN JIMÉNEZ, M.I., HORTELANO MÍNGUEZ, L.A. y PLAZA GUTIÉRREZ, J. I. (2007): «Cooperación territorial y gobierno del territorio en Castilla y León», Estudios Geográficos, n ${ }^{\circ} 263$, pp. 547-574.

PLAZA GUTIÉRREZ, J.I. (2000): «Incidencia y alcance del turismo rural en las comarcas fronterizas de la provincia de Zamora», en Los espacios rurales en el cambio de siglo: 
incertidumbres ante los procesos de globalización y desarrollo, Actas del X Coloquio de Geografía Rural de España. Lleida, Universitat de Lleida y Asociación de Geógrafos Españoles (AGE), pp. 346-354.

PLAZA GUTIÉRREZ, J.I. (2000): «El turismo rural en territorios periféricos (El ejemplo de algunas comarcas del oeste castellano-leonés», Investigaciones Geográficas, $\mathrm{n}^{\circ} 27$, pp. 83-106.

PLAZA GUTIÉRREZ, J.I. y HORTELANO MÍNGUEZ, L.A. (2002): «Actuaciones y propuestas para el uso público del patrimonio natural en comarcas fronterizas de Castilla y León (algunos ejemplos y valoración de los mismos)». En: Blázquez, M.; Cors, M.; González, J.M. y Seguí, M. (Coords.). Geografía y Territorio. El papel del geógrafo en la escala local. Palma de Mallorca, Asociación de Geógrafos Españoles (AGE)-Association Francaise pour le Dévelopement de la Géographie (AFDG). Universitat de les Illes Balear, pp. 269-278.

SALINAS DE FRÍAS, M. (Coord.) (2013): Interpretar La Frontera. Salamanca, Ediciones de la Diputación Provincial.

SÁNCHEZ LÓPEZ, F.; CABERO DIÉGUEZ, V. y MARTÍN HERNÁNDEZ, J. T. (1993): Frontera y Desarrollo. El programa transfronterizo de España y Portugal. Salamanca, Instituto de Recursos Naturales y Agrobiología y Departamento de Geografía de la Universidad de Salamanca.

SÁNCHEZ LÓPEZ, F. y CABERO DIÉGUEZ, V. (1994): La frontera hispano-portuguesa en el marco de la nueva Europa: la región fronteriza de Salamanca. Salamanca, Instituto de Recursos Naturales y Agrobiología y Departamento de Geografía de la Universidad de Salamanca. 